\title{
The Collaborative Construction of the Clinical Mind: Excellence in Patient Care through Cognitive Integration of Basic Sciences Concepts into Routine Clinical Practice
}

\author{
Leslie H. Fall ${ }^{1}$
}

Published online: 20 October 2015

(C) International Association of Medical Science Educators 2015

Why do physicians require a strong foundational understanding of the basic sciences to routinely provide safe and effective clinical care? How do basic science and clinical educators collaborate to ensure medical students graduate with a fully integrated and applicable knowledge base? On the surface, these seem simple questions, and yet simple answers elude us as we engage in ongoing cycles of curriculum reform. Certainly, few would argue that the explosion in biomedical discoveries and the expansion of translational research demand that today's physician understand the sciences relevant to the newest diagnostic testing and therapies. Further, most physician educators I've spoken with strongly believe that excellent clinicians 'think like scientists' - applying an investigator's mind to the patient who presents with unusual symptoms, responds unexpectedly to standard therapy, or doesn't respond at all-implying that the early years of the medical curriculum provide a physician with these skills. But do they?

\section{A History of Effective Collaboration}

In many ways, Flexner deserves credit as the father of integrating the basic sciences, and basic science faculty, into clinical medicine at a programmatic level [1]. Following his landmark 1910 report and ensuing changes to accreditation standards, medical schools began providing each student with a rigorous pre-clinical education in the scientific method and the

Leslie H. Fall

leslie.fall@med-u.org

1 Geisel School of Medicine at Dartmouth and MedU Co-founder and Executive Director, Hanover, NH, USA biologic underpinnings of medicine. In the early part of the century, without today's undergraduate pre-medical curriculum, this distinctly separate science education was both novel and necessary. Basic science faculty taught using their own research as the curriculum, much as clinical faculty relied on their patients for teaching. In this manner, both ensured that young clinicians graduated with a cutting edge knowledge base and a strong exposure to both the scientific and the clinical mind.

The divided curriculum worked effectively for nearly 50 years until the post-war explosion in biomedical research pushed scientists deeper into the cell and often away from common clinical application. Furthermore, basic science faculty began feeling today's pressure to continuously widen the scope of information to 'cover' and assess, arguably beyond what students could reasonably be expected to learn and routinely apply in practice. Partly in response to these challenges, problem-based curricula began to emerge in the early 1970s, pushing integration for the first time to the course and session level [2]. Curriculum leaders also encouraged collaborative discussions between basic science and clinical faculty to identify relevant medical conditions, albeit many of them uncommon or rare, that best exemplified the clinical context for scientific principles. Students religiously attended class and took copious notes, later transcribing these into pocket-sized journals, or 'peripheral brains,' thereby integrating the sciences themselves as they meticulously updated their notes throughout the clerkships.

Today the rapidly changing healthcare system and emergence of information technology has added unprecedented complexity and angst to our medical education system. Learning management systems, online resources, tablet computers, and video recorded lectures have all but replaced faceto-face basic science teaching. Gone is the luxury of steeping students in the scientific mind, as a faculty's area of research 
and passion may now be considered irrelevant or unworthy of increasingly limited curricular time. Many basic science educators, once beloved by medical students, now find themselves questioning their relevance in the curriculum. Clinical faculty, chasing clinical productivity measures and the clock, often lament that taking time to think like a scientist and to integrate basic sciences into their teaching is a luxury they can rarely afford. Mired within these challenges, have we as educators lost our cooperative path?

Collaboration can be defined as two or more people working together towards shared goals. To be effective, collaboration requires a team with a shared language, a shared method and a shared purpose. By returning to our historic roots, can we solve the integration problem by working as a team to develop our students' minds for their practice? I believe we can.

\section{The Expert Clinical Mind: From Cognitive Integration to Encapsulation}

Watching my own daughter run the academic gauntlet through the first years of medical school, these questions have taken on a new and personal importance for me. She and her peers both trust and demand to know that the nights, weekends, and special occasions they sacrifice-memorizing, memorizing, and memorizing - are all in the service of their future excellence as clinicians. Are we living up to their trust? Unfortunately, I don't think we do. Despite our recent curricular innovations, most students persistently hear from clinical teachers that they will rarely use their basic science knowledge in practice. True to form, students find they are infrequently asked to justify the basic science foundations of their clinical reasoning. Why? Have our reforms, revisions, and renews been for naught? Or are we simply approaching the integration problem from the wrong direction?

For years, medical education research supported the impression that seasoned clinicians drew infrequently from their basic science knowledge [3, 4]. More recently, Woods and her colleagues report that experienced physicians do indeed rely on their scientific knowledge in practice, but their knowledge is highly encapsulated and difficult to intentionally access [5]. These findings are consistent with deep domain knowledge in other fields as well. Cognitive load theory posits that our brain's limited capacity for active working memory, the magic $5 \pm 2$, requires progressive 'chunking' of learned information in order expand cognitive abilities [6]. Extensive and repeated use of given chunks of information promotes encapsulation and explains the tacit understanding - or unconscious competence - characteristic of an expert. Unfortunately, encapsulation creates a difficult situation for experienced faculty teaching novice learners who require expert knowledge to be effectively deconstructed and continuously available for their learning [7]. Master teachers recognize this phenomenon and work to deliberately maintain a state of 'conscious competence' for their students, even as they work to expand their own expertise.

Thus, solving the integration problem originates at the cognitive level-in the earliest moments when our students begin to see and learn the links between science and medicine. Woods and her colleagues have demonstrated that novice diagnosticians require teachers to deliberately integrate the relevant sciences with the clinical findings they support at a very granular, nearly sentence-by-sentence, level [8-10]. Students continue to build a useful cognitive network by meaningfully relating these small knowledge 'packages' to one another through further examples $[11,12]$. What begins as a fairly dispersed cognitive landscape of limited, jumbled, and misfiled information in the student's mind becomes with time, learning, and experience, a progressively better organized, elaborated, and enriched network of linked concepts that continuously roll up into progressively higher order understanding [13]. Faculty who employ relevant analogies, diagrams, and stories in their teaching further facilitate student's conceptual understanding, recall and long-term memory [14, 15]. At this stage, students who engage in exercises that promote application and transfer of their conceptual understanding to challenging clinical problems engineered with desirable difficulty have been shown to develop early adaptive expertise [7, $14,15]$. Hence, basic science educators are charged with the most formative stages of 'cognitive packing' for a clinician's lifelong intellectual journey.

Through my own curriculum development work, I have learned that my scientist colleagues' domain knowledge is as encapsulated as my own. Additionally, relatively similar information is organized very differently in their minds, which may have important implications for why we find integrated curriculum development and teaching surprisingly difficult. Cognitive problem solving for scientists begins with a known disease or condition. The environment is intentionally controlled and the reasoning process involves a seemingly endless series of questions, the answers to which progressively build a deeper and richer cognitive understanding of the focused biologic processes in question. Scientists deliberately make decisions using the full context of this rich understanding; effort and success are measured in years. Cognitive problem solving for clinicians frequently begins only with a symptom or constellation of symptoms. The time available for exploratory questions (Why does this infant have a fever? What are the various causes of an infection in a newborn to be considered?) is often measured in minutes before the first decision-driven questions begin (What is the most likely diagnosis in this infant? What additional work-up should be done? What therapy should I use? What is likely to happen to this patient tonight and what orders should I write?). These questions are then answered in rapid succession, even as thinking about the next 
patient commences. Effort and success may be measured in minutes, hours, or days. While a physician's knowledge base is similar and no less rich than a scientist's, effective application demands rapid decision-making in an environment that is highly variable, complex, ambiguous, and at times risky.

I am also struck by how little my basic science colleagues understand about the clinical reasoning process, particularly in the context of daily patient care. Researchers have studied how physicians think and arrive at decisions for decades, and an extensive review of the literature is out of the scope of this essay [16-18]. In general, as soon as a clinician's mind begins to consider a clinical problem, decision-making begins through two relatively simultaneous cognitive processes. The first is rapid and intuitive and involves an extensive degree of pattern recognition. The brain efficiently recognizes, compares, and contrasts patterns, so that even novice diagnosticians quickly learn to employ this system. The second is slower and more deliberative, forcing the brain to calibrate its pattern-based conclusions against more explanatory models both during initial pattern processing as well as prior to reaching a final conclusion. Thus, in practice, cognitive integration occurs in the interface between the two systems, where causal basic science understanding is activated to confirm, question, or reject intuitively generated patterns. To use basic sciences effectively in practice, clinicians must be able to access relevant networks of related concepts quickly and efficiently to construct a temporary mental framework, unique to each patient problem, which might explain a given clinical hypothesis or justify a decision. Ongoing clinical experience provides opportunity to further refine and expand conceptual networks.

\section{A New Collaboration: Creating Cognitive Apprenticeships for Learners}

To promote better cognitive integration in our learner's minds, basic science and clinical educators must first find a mutually beneficial teaching language. A core set of agreed upon basic science concepts, each with an articulated clinical rationale that demonstrates application to everyday practice, can serve as the common ground. Teaching from this core, basic science educators assure that students achieve the pre-requisite knowledge base required for higher-order conceptual understanding. Subsequently, clinical educators can build on this understanding to demonstrate how each concept is applied across the clinical continuum. A shared understanding also prevents important basic science content from being inappropriately eliminated from the curriculum through the mistaken impression that clinicians don't apply the information in practice. By the same token, basic science educators must articulate how each concept supports important clinical decisions, either today or in the future, thereby providing a more effective lens for curricular focus.

Leveraging this shared understanding, basic science and clinical educators will find integrated teaching sessions much easier to collaboratively develop and teach. Cognitively integrated decision-making, like other clinical skills, is highly complex and true expertise requires hours of applied deliberate practice $[15,19]$. To enable this practice, integrated curricula and teaching must move beyond courses and sessions, beyond the straightforward exemplars that rare diseases and novel therapies provide, and beyond basic science discussions in the context of an interesting and complex patient, to realistic practice with conditions and diagnoses encountered routinely on the inpatient units and in clinics. Developed by teams of basic science and clinical educators, simulated and virtual patient encounters can provide students with a structured 'cognitive apprenticeship' for new skills in integrated decisionmaking. Collaborative development of virtual patients on a common platform is an effective method for designing and delivering medical education with broad curricular impact $[20,21]$. Through multiple examples of similar and varied patient presentations, with progressively increased difficulty and feedback delivered when needed, virtual experiences help students gradually learn to self-calibrate their decision-making speed and accuracy as needed, supporting the primary tenets of adaptive expertise development [7, 12, 15, 22-25]. Virtual cases also provide a model for new teaching methods and serve as tools for clinical faculty development.

\section{First, Do No Harm}

Delayed or missed diagnosis, unnecessary or harmful testing, incorrect, unnecessary or unnecessarily expensive medications or combinations of medications all lead to iatrogenic harms and wasted resources in our healthcare system. Cognitively integrated decision-making can improve healthcare value and promote safer patient care. To provide excellent care, a physician must first create the most accurate picture, in their own mind, of the integrated processes naturally occurring within the human body of each unique patient. Clinicians with well-developed habits of mind integrate not only pattern recognition and evidence-based medicine, but also their strong conceptual understanding of the basic sciences in order to recommend the most accurate and timely diagnosis, the most valuable diagnostic or management plan, or anticipate correctly the most likely course of illness for each individual patient.

To provide students with a cognitive apprenticeship that promotes integrated decision-making in actual clinical practice requires faculty with strong coaching skills and an ability to routinely deconstruct their own thinking [26]. To do 
so, clinical teachers will require assistance from their basic science colleagues in the form of relevant and accessible basic science teaching tools. Developed together from a conceptual core, these tools must be linked to commonly encountered conditions and decisions, support the fluidity of real-time clinical reasoning, and clearly articulate how the application of basic science principles provides real clinical value and avoids harm.

For this effort, clinician teachers will find that students with a clear understanding of the basic science concepts that underlie sound clinical judgment are better equipped to justify their decisions and assume clinical responsibilities. Moreover, clinical educators will now have a stronger foundation from which to entrust students' transition from supervised to unsupervised decision-making and clinical practice [27, 28].

\section{Basic Science Education Belongs at the Bedside Everyday}

Cognitive integration occurs not only in the minds of a physician, but within the minds of patients and members of the healthcare team as well. Effective integration is manifest in the shared understanding a patient develops with her physician as they work together to agree upon the best course of action, and in the collaborative actions of a well functioning team. Poor patient understanding and adherence, under-informed consent and questionable shared decision-making, and imprecise team communication all lead to iatrogenic harms and unnecessary expense. Our healthcare system needs basic science educators, working side-by-side with clinical educators, to entrust that each graduating physician can effectively communicate relevant basic sciences concepts to their patients and their colleagues. Common but accurate analogies, pictures, and stories, well practiced and easily retrieved in a clinician's mind, may go a long way towards eliminating the potential harms that scientific misunderstanding by patients may produce [29]. Thus, basic science faculty have as much duty to improve the value and the safety of the care that our graduating physicians learn to provide to their patients every day. Our students, and their patients, deserve nothing less from both of us.

Acknowledgments I am indebted to all members of the MedU Science integrated curriculum development teams who have selflessly, courageously, and passionately contributed their own thinking, extensive personal experience, diligent hard work, patience and faith, and without whom this work would not be possible. I am also deeply grateful to the medical students and residents and the patients who have guided my thinking and my own expertise development over the years. They have truly been my teachers and remain my primary inspiration on this journey. And for Lauren - may your own practice excel well beyond my own.

\section{References}

1. Ludmerer KM. A time to heal: American medical education from the turn of the century to the era of managed care. Oxford: Oxford University Press; 2005.

2. Goldman E, Schroth WS. Deconstructing integration: a framework for the rational application of integration as a guiding curricular strategy. Acad Med. 2012;87(6):729-34.

3. Patel VL, Evans DA, Groen GJ. Biomedical knowledge and clinical reasoning. In: Da E, Patel VL, editors. Cognitive sciences in medicine. Cambridge: MIT Press; 1988. p. 53-112.

4. Patel VL, Groen GJ, Scott HM. Biomedical knowledge in explanations of clinical problems by medical students. Med Educ. 1988;22: 398-406.

5. Woods NN, Neville AJ, Levinson AJ, Howey EHA, Oczkowski WJ, Norman GR. The value of basic science in clinical diagnosis. Acad Med. 2006;81(10 Suppl):S124-7.

6. Clark RC, Nguyen F, Sweller J. Efficiency in learning: evidencebased guidelines to manage cognitive load. San Francisco: Pfeiffer; 2006.

7. Bereiter C, Scardamalia M. Surpassing ourselves: an inquiry into the nature and implications of expertise. LaSalle: Open Court; 1993.

8. Woods NN. Science is fundamental: the role of biomedical knowledge in clinical reasoning. Med Educ. 2007;41:1173-7.

9. Kulasegaram KM, Martimianakis MA, Mylopoulos M, Whitehead CR, Nicole N, Woods NN. Cognition before curriculum: rethinking the integration of basic science and clinical learning. Acad Med. 2013;88(10):1578-85.

10. Baghdady MT, Carnahan H, Lam EWN, Woods NN. Integration of basic sciences and clinical sciences in oral radiology education for dental students. J Dent Educ. 2013;77(6):757-63.

11. King JF, Goodson L, Rohani F. Higher order thinking skills [Internet]. Available from: http://www.cala.fsu.edu/files/higher order thinking skills.pdf.

12. Stalmeijer RE, Dolmans DHJM, Snellen-Balendong HAM, van Santen-Hoeufft M, Wolfhagen IHAP, Scherpbier AJJA. Clinical teaching based on principles of cognitive apprenticeship: views of experienced clinical teachers. Acad Med. 2013;88(6):861-5.

13. Bordage G. Elaborated knowledge: a key to successful diagnostic thinking. Acad Med. 1994;69(11):76-7.

14. Norman GR. Teaching basic science to optimize transfer. Med Teach. 2009;31:807-11.

15. Brown PC, Roediger HL, McDaniel MA. Make it stick: the science of successful learning. Cambridge: Belknap; 2014.

16. Crosskerry P. A universal model of diagnostic reasoning. Acad Med. 2009;48(8):1022-8.

17. Eva KW. What every teacher needs to know about clinical reasoning. Med Educ. 2004;39:98-106.

18. Bowen J. Educational strategies to promote clinical diagnostic reasoning. NEJM. 2006;355(21):2217-25.

19. Ericsson KA. Deliberate practice and the acquisition and maintenance of expert performance in medicine and related domains. Acad Med. 2004;79(10 Suppl):S70-81.

20. Fall LH, Berman NB, Smith S, White CB, Woodhead JC, Olson AL. Multi-institutional development and utilization of a computerassisted learning program for the pediatrics clerkship: the CLIPP project. Acad Med. 2005;80:847-55.

21. Berman NB, Fall LH, Chessman AW, Dell MR, Lang VJ, Leong SL, et al. A collaborative model for developing and maintaining virtual patients for medical education. Med Teach. 2001;33:31924.

22. Norman GR, Young M, Brooks L. Non-analytical models of clinical reasoning: the role of experience. Med Educ. 2007;41:1140-5. 
23. Artino AR, Cleary TJ, Dong T, Hemmer PA, Durning SJ. Exploring clinical reasoning in novices: a self-regulated learning microanalytic assessment approach. Med Educ. 2014;48: 280-91.

24. Moulton CE, Regehr G, Mylopoulos M, MacRae HM. Slowing down when you should: a new model of expert judgment. Acad Med. 2007;82(10 Suppl):S109-16.

25. Hodges BD, Lingard L. The question of competence: reconsidering medical education in the twenty-first century. Ithaca: Cornell University Press; 2014.
26. Gifford KA, Fall LH. Doctor Coach: a deliberate practice approach to teaching and learning clinical skills. Acad Med. 2014;89:272-6.

27. Pangaro L. The role and value of the basic sciences in medical education: the perspective of clinical education - students' progress from understanding to action. JIAMSE. 2010;20(3):307-13.

28. Core entrustable activities for entering residency. Association of American Medical Colleges. 2014. Available from: https://www. aamc.org/cepaer

29. Alan Alda Center for Communicating Science. http://www. centerforcommunicatingscience.org/alan-alda/ 